\title{
REGULAÇÃO E DESENVOLVIMENTO ECONÔMICO: UMA ANÁLISE CRÍTICA E INTERDISCIPLINAR EM DIREITO E ECONOMIA
}

RESUMO: Este artigo aproveita-se do profícuo debate interdisciplinar sobre regulação para poder analisar, comparativamente, como Direito e Economia, as duas áreas do conhecimento de maior impacto nesse estudo, posicionam-se acerca de uma questão específica: as peculiaridades da regulação em contextos de desenvolvimento, particularmente em economias em transição, como o Brasil. É sabido que acadêmicos do Direito e da Economia, em conjunto, desenvolveram ferramentas interdisciplinares sofisticadas nas últimas décadas, aplicáveis a objetivos de pesquisa que resultariam incompletos se aprisionados a disciplinas isoladas e isso torna relevante a compreensão de como esse problema é - ou pode ser - interpretado por meio dessas duas diferentes visões. Para tanto, parte-se dos principais tratamentos teóricos tradicionalmente empregados à regulação, do exame do caráter e abrangência das reformas regulatórias do final do século $X X$ e da descrição das três principais "lentes interpretativas" em Direito e Economia com o objetivo de teorizar acerca da conciliação entre elas. Como conclusão, entende-se que está em plena construção uma veia interpretativa que ofereça uma moldura analítica que aporte à regulação tanto objetivos inescapáveis de eficiência econômica e estabilidade institucional quanto a necessária flexibilidade que processos de desenvolvimento requerem.

Palavras-Chave: Direito e Economia; Regulação; Desenvolvimento econômico.

\footnotetext{
${ }^{1}$ Doutorando em Políticas Públicas, Estratégias e Desenvolvimento (PPED) no Instituto de Economia da Universidade Federal do Rio de Janeiro (IE/UFRJ) e Mestre em Regulação de Serviços Públicos pela London School of Economics and Political Science (LSE); Especialista em Políticas Públicas e Gestão Governamental (EPPGG) no Instituto de Pesquisa Econômica Aplicada (Ipea). E-mail: bruno.cunha@ipea.gov.br.
} 


\title{
REGULATION AND ECONOMIC DEVELOPMENT: A CRITICAL AND INTERDISCIPLINARY ANALYSIS IN LAW AND ECONOMY
}

\begin{abstract}
This article takes advantage of the proficient interdisciplinary debate on regulation to be able to analyze, comparatively, as Law and Economy, the two areas of knowledge with the greatest impact in this study, stand on a specific issue: the peculiarities of regulation in development contexts, particularly in transition economies such as Brazil. It is well known that Law and Economics scholars together have developed sophisticated interdisciplinary tools in the last decades, applicable to research objectives that would be incomplete if imprisoned in isolated disciplines, and this makes relevant the understanding of how this problem is - or can be - interpreted through these two different views. The paper departs from examining the main theoretical treatments traditionally employed in regulation, the character and scope of the regulatory reforms of the late twentieth century and the description of the three main "interpretive lenses" in Law and Economics with the objective of theorizing about the conciliation between them. As a conclusion, it is understood that the construction of an interpretive vein that offers an analytical framework that contributes to regulation inescapable goals of economic efficiency and institutional stability as well as the necessary flexibility that development processes require is well underway.
\end{abstract}

KEYWORDS: Law and Economics; Regulation; Economic development. 


\section{REGULAÇÃO E DESENVOLVIMENTO ECONÔMICO: UMA ANÁLISE CRÍTICA E INTERDISCIPLINAR EM DIREITO E ECONOMIA}

\section{INTRODUÇão}

Regulação é um tema recorrente tanto no Direito quanto na Economia. No debate teórico sobre o assunto, são esses dois campos das ciências sociais que detêm influência preponderante, pois logram moldar os principais conceitos e determinar a prática da regulação em linha com seus instrumentos metodológicos. Por um lado, pode-se afirmar que essa preponderância apenas repercute a natureza eminentemente interdisciplinar da regulação; além do domínio da linguagem jurídica e econômica no campo das políticas públicas como um todo (SARAVIA, 2006).

Por outro lado, contudo, o predomínio das ciências jurídicas e econômicas com relação ao construto interdisciplinar da regulação é crescentemente disputado por outros campos das ciências sociais, que avançam vias interpretativas complementares. A Ciência Política, por seu turno, reivindica papel de destaque no estudo do tema. A Administração, seja nas ferramentas e programas de pesquisa que compartilha com outros ramos das ciências sociais - inclusive Economia e Direito -, seja no que lhe é mais próprio, como o terreno da gestão pública e privada, também contribui para o estudo da regulação. A lista é longa, e da Sociologia à Psicologia, passando pela História, cientistas sociais de diferentes departamentos empregam métodos alternativos para analisar a regulação enquanto elemento da vida social.

Diante disto, é intenção deste artigo aproveitar-se desse profícuo debate interdisciplinar de maneira a poder analisar, comparativamente, como as duas áreas do conhecimento de maior impacto no estudo da regulação posicionam-se acerca de questão específica: as peculiaridades da regulação em contextos de desenvolvimento, particularmente em economias em transição, como o Brasil. É sabido que acadêmicos do Direito e da Economia, em conjunto, desenvolveram ferramentas interdisciplinares sofisticadas nas últimas décadas, aplicáveis a objetivos de pesquisa que resultariam incompletos se aprisionados a disciplinas isoladas. A regulação é tema natural para esse tipo de interdisciplinaridade (ESTEVES, 2010; ZYLBERSZTAJN; SZTAJN, 2005), o que torna relevante compreender como problemas afetos ao tema são ou podem ser - interpretados por meio de diferentes lentes em Direito e Economia.

Para tal, o presente artigo tem como pano de fundo o contexto internacional de reformas regulatórias liberalizantes, que se transmutou em movimento de proporções globais ao longo dos anos 1980 e 1990. Essas reformas assentaram-se sobre uma matriz teórica determinada, fato que será investigado criticamente neste trabalho, de maneira a que se compreendam seus pontos mais sensíveis, além das peculiaridades aplicáveis aos países em desenvolvimento. 


\section{REVISTA ESTUDOS INSTITUCIONAIS}

$\mathrm{Na}$ primeira parte do trabalho, serão revistos os principais tratamentos teóricos tradicionalmente empregados à regulação, além de examinados o caráter e a abrangência das reformas regulatórias do final do século XX e seus principais efeitos sobre a estrutura de Estado. Ainda nessa parte, serão discutidas particularidades que dizem respeito a contextos de economias em transição, as quais levantam dúvidas indispensáveis sobre a conformação dos limites e escopo da regulação.

A segunda parte do artigo descreverá as lentes interpretativa em Direito e Economia que podem carrear contribuições relevantes para o objeto de análise proposto. Inicialmente, detalhar-se-á a vertente do Law $\mathcal{E}$ Economics, ou Análise Econômica do Direito, na acepção mais própria da Escola de Chicago. Seguirá daí a discussão acerca da segunda lente interpretativa, a da Nova Economia Institucional, com destaque para a chamada Economia dos Custos de Transação. A terceira e última vertente será a do Direito e Desenvolvimento, que, similarmente às duas anteriores, empresta elementos em prol do aprofundamento do tema em análise.

Ao final, serão apresentadas as conclusões do trabalho. Neste momento, será possível teorizar acerca da conciliação entre as três lentes interpretativas de Direito e Economia apresentadas, posto que, em conjunto e preservando a característica interdisciplinar, alimentam complementariedades benéficas ao debate em regulação e desenvolvimento. A despeito dos embates teóricos e prováveis conflitos entre as três vertentes, parece tanto inovador, no plano teórico, quanto producente para a operacionalização real da regulação na prática a busca pela aplicação combinada dessas três vertentes interpretativas.

\section{TEORIA DA REGULAÇÃO E REFORMAS REGULATÓRIAS}

\section{Regulação e Estado Regulador}

A teoria e a prática da regulação estão predominantemente referenciadas ao pensamento econômico neoclássico, segundo o qual a atuação regulatória por parte do Estado - e o papel relativo da sociedade - tem caráter ancilar ao do mercado (CHANG, 1997). Neste contexto, a regulação estatal é vista como second-best, ou seja, uma solução secundária, inferior à organização da produção e do consumo pelo mercado, isoladamente (PROSSER, 2006).

Essa visão teórica acerca da regulação alcançou proporções globais entre as décadas de 1980 e 1990, constituindo-se assim na base conceitual 


\section{REGULAÇÃO E DESENVOLVIMENTO ECONÔMICO: UMA ANÁLISE CRÍTICA E INTERDISCIPLINAR EM DIREITO E ECONOMIA}

para o surgimento do que se convencionou chamar de Estado regulador. Esse modelo institucional surgiu, essencialmente, como um modo de atuação estatal organizado dentro de premissas econômicas liberalizantes, e inspirado por uma lógica anti-estado e market-friendly (PRADO, 2013).

Majone (1997), tomando como ponto de partida para sua análise principalmente o contexto europeu de reformas regulatórias, conceitua o Estado regulador a partir da distinção com o Estado produtor (ou "positivo"). Segundo Majone, o Estado regulador é aquele mais detido à normatização e ao monitoramento do que à produção de bens e serviços, ou à intervenção direta na economia e na vida social (MAJONE, 1997). Esse modelo de Estado, portanto, estaria voltado a induzir o desenvolvimento, ao invés de produzi-lo diretamente.

Todavia, a interpretação econômica convencional acerca da regulação encerra visão parcial deste instrumento de políticas públicas. Em verdade, trata-se de um posicionamento de tipo prescritivo ou normativo (YEUNG, 2010), haja vista que a correção de falhas de mercado ${ }^{2}$ e a promoção da competição entre os agentes regulados, seus propósitos centrais declarados, embora tecnicamente aceitáveis, correspondem a apenas parte da atividade regulatória estatal em vigor na maior parte dos países do mundo (VELJANOVSKI, 2010). Jordana e Levi-Faur (2004) lembram que, numa visão positiva (do 'ser'), regulação pode receber ao menos três conceituações, a depender do grau de abrangência que se pretenda atribuir ao termo, a saber:

I. Regulação como normatização (mais restritivo) - diz respeito ao regramento do exercício de atividades privadas por parte de organizações públicas (ex.: agências reguladoras).

II. Regulação como todas as formas de intervenção do Estado na economia e na vida privada (intermediário) - inclui tributação, subsídios e propriedade estatal de estruturas produtivas.

\footnotetext{
${ }^{2}$ Em síntese, as falhas de mercado são essencialmente dos seguintes tipos: (1) Poder de mercado, que permite o estabelecimento de preços acima dos níveis de concorrência perfeita; (2) Externalidades, positivas ou negativas, que são situações em que o comportamento de um indivíduo afeta outros agentes sem que isto passe pelo sistema de preços; (3) Bens públicos, para os quais o consumo será não rival e não excludente, determinando um subinvestimento na provisão do bem ou serviço; e (4) Assimetria de informação, situação na qual um das partes da transação detém um conjunto mais completo de informações do que a outra, e com isto pode agir oportunisticamente para auferir lucros.
} 


\section{REVISTA ESTUDOS INSTITUCIONAIS}

III. Regulação como controle social de todos os tipos, inclusive informais e não-estatais (mais abrangente).

Jordana e Levi-Faur (2004, p. 03) representam graficamente essas diferenças conceituais da maneira exposta na figura abaixo, a qual denota que cada um dos possíveis sentidos de regulação contém também o significado atribuído ao termo na definição de natureza mais restritiva.

Figura 1 - os três sentidos da regulação

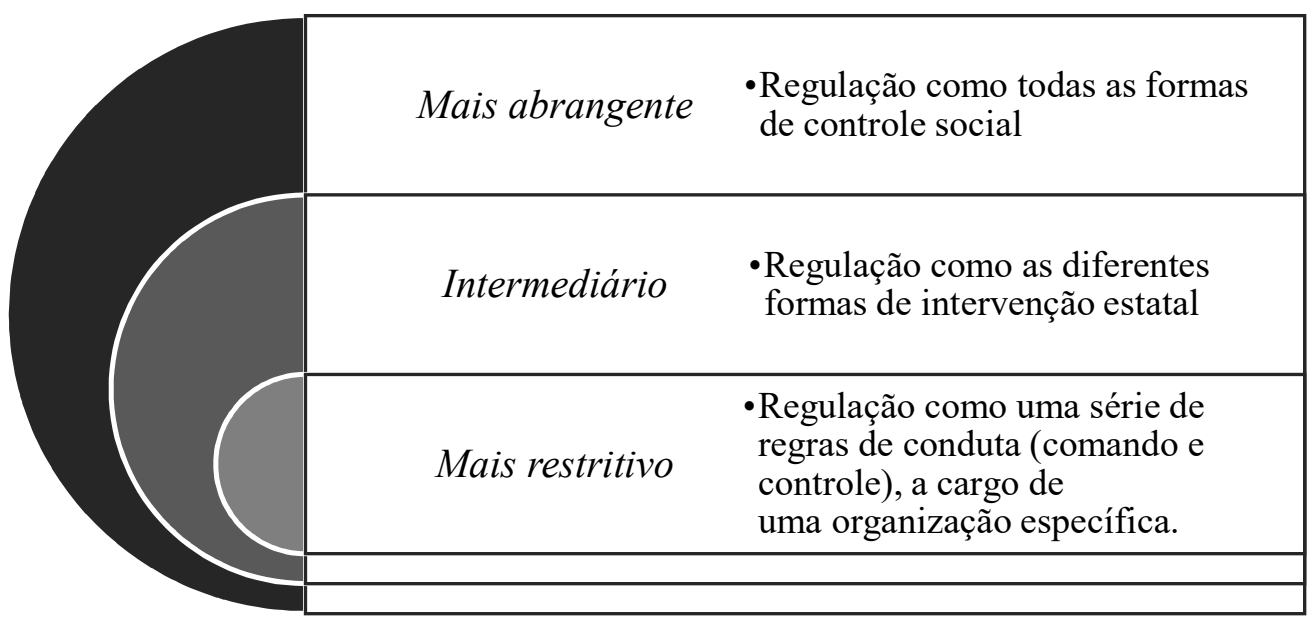

Fonte: adaptação a partir de Jordana e Levi-Faur (2014)

Como o objetivo deste trabalho não é revisar toda a discussão teórica acerca do conceito da regulação, o termo será aqui entendido pela acepção mais restritiva, conforme acima. Nesse sentido, utilizando Ogus (2001, p. 141), a regulação pode ser delimitada da seguinte forma: "a área do direito público que implementa metas coletivas, ou seja, por meio da qual o Estado busca determinar ou encorajar comportamentos que (assume-se) não ocorreriam sem intervenção... atendendo a metas de interesse público" ${ }^{\prime 3}$.

Com relação às razões de regular e aos objetivos da regulação, contudo, a base teórica aqui empregada é predominantemente crítica. Esta se opõe à visão convencional neoclássica, para a qual a regulação é cativa do mundo das falhas de mercado e da promoção de competição estática. Essa opção teórica, à qual nos filiamos, não implica em afirmar

\footnotetext{
3 Em tradução livre.
} 


\section{REGULAÇÃO E DESENVOLVIMENTO ECONÔMICO: UMA ANÁLISE CRÍTICA E INTERDISCIPLINAR EM DIREITO E ECONOMIA}

que a visão neoclássica é, em si, desprovida de valor; mas, sim, que tal abordagem é altamente incompleta (SUSTEIN, 1993; PROSSER, 1997, 2006; MARTINS, 2011; MATTOS, 2006; COUTINHO, 2014).

A correção de falhas de mercado e a busca por eficiência econômica se justificam em virtude de uma decisão política de priorização de resultados economicamente eficientes, o que não deve ser naturalizado ou tido como verdade científica (CHANG, 1997; PROSSER, 2006). Ou seja, não significa que outros princípios e valores, inclusive de ordem social, moral, histórica ou cultural, também não possam integrar programas regulatórios (FEINTUCK, 2010). Como esclarecem Lodge e Wegrich (2012, p. 25): "regulação diz respeito à competição entre valores e, portanto, argumentos de falhas de mercado não devem gozar de superioridade sobre outros tipos de argumentos" ${ }^{4}$.

Notoriamente, a divisão de rendas e os custos advindos de diferentes desenhos regulatórios pode se alterar, como resultado da modificação do escopo da regulação. Isso, contudo, é algo que deve ser claramente explicitado e suas consequências, deliberadas democraticamente, afastando-se desde o início qualquer aquiescência apriorística à supremacia de argumentos puramente econômicos (CHANG, 1997). As diferentes alternativas de escolhas possíveis para a política regulatória lhe asseguram um conteúdo aberto que não se confunde, portanto, com um subproduto da ideologia neoliberal (COUTINHO, 2014; DUBASH E BROWEN, 2013). A dosagem ou o trade-off entre os princípios e valores que induzem regulação, igualmente, resulta de decisão de ordem política, o que ocorre em estreita vinculação às preferências de uma sociedade em um dado momento histórico (PROSSER, 2006).

Vale lembrar que a mais liberal e economicista das visões vê com reservas qualquer tipo regulação, mesmo em virtude de falhas de mercado. Nesse caso, é referência a Escola de Chicago, que radicaliza na oposição a instituições de monitoramento e coordenação estatais e recomenda o engajamento com iniciativas de desregulamentação da economia, no sentido da retração do Estado (STIGLER, 1971; PELTZMAN, 1976). Essa interpretação é a base da chamada Teoria Econômica da Regulação e da Teoria da Captura. Segundo elas, a busca do interesse público por meio do emprego da regulação muito provavelmente induziria a uma intromissão desmedida e possivelmente danosa do Estado, pois os agentes públicos ou não deteriam meios e competência suficientes para fazê-lo de forma eficiente ou, ainda que o tivessem, agiriam imbuídos de interesses individualistas maximizadores de suas próprias utilidades, o que abriria espaço para a ocorrência de falhas de governo, ou falhas regulatórias (OGUS, 2004). Diante dessa ameaça, qualquer regulação é vista, de antemão, como ineficiente.

\footnotetext{
${ }^{4}$ Em tradução livre.
} 


\section{REVISTA ESTUDOS INSTITUCIONAIS}

Foi em meio ao debate teórico do qual saiu vencedora a tese econômica convencional, ainda que atenuada quando do desdobramento prático de reformas, que se promoveram abrangentes incursões liberais nos anos 1980 e 1990, inicialmente no mundo desenvolvido. Na Europa continental, partiu-se para a retração do Estado de bem-estar; nos Estados Unidos, já comparativamente mais amigáveis ao liberalismo econômico, a proposta foi na direção da agenda da desregulamentação (MARTINS, 2011). O Reino Unido se situou em posição mais ou menos intermediária entre esses dois regimes (MORAN, 2003).

\section{Regulação em Países em Desenvolvimento}

Precedentes de países desenvolvidos nortearam as reformas administrativas no campo da regulação ao redor do mundo, a partir do final dos anos 1980. No Brasil, avançou-se na institucionalização do papel regulador do Estado por intermédio de alterações normativas, inclusive em âmbito constitucional, e da criação de agências reguladoras de caráter independente (FARIAS; RIBEIRO, 2014).

Em grande parte do mundo em desenvolvimento, a influência da vertente teórica liberalizante veio acompanhada de intensa pressão política e econômica internacional pró-reformas. A perpetuação de graves situações de endividamento tornaram países em desenvolvimento reféns de seus credores internacionais (CHANG, 1997). Muitos dos itens das reformas, inclusive uma ampla pauta de privatizações, era determinada por instituições financeiras internacionais e configuravam condicionantes para a liberação de recursos de empréstimos (ESTACHE; WREN-LEWIS, 2009; MINOGUE, 2002; PRADO, 2014). Porém, a dependência financeira não foi o único canal de transmissão de ideias e modelos.

Numa análise da influência do legado ideológico sobre processos de reforma nos serviços públicos na América Latina no final do século XX, Martinez-Gallardo e Murillo (2011, p. 353) afirmam: "legados ideológicos proveram aos políticos regras de bolso para serem adotadas na interpretação das escolhas institucionais no tocante à regulação" ${ }^{\prime \prime}$. A dependência teórica, no contexto latino-americano, toma papel de destaque como promotor das reformas regulatórias, inclusive na constituição de agências reguladoras de caráter independente (JORDANA; LEVI-FAUR, 2004; CUNHA; RODRIGO, 2012; PRADO, 2014).

${ }^{5}$ Em tradução livre. 


\section{REGULAÇÃO E DESENVOLVIMENTO ECONÔMICO: UMA ANÁLISE CRÍTICA E INTERDISCIPLINAR EM DIREITO E ECONOMIA}

A subscrição do Brasil a reformas liberais e a consequente construção de uma agenda regulatória alinhada às boas práticas internacionais envolvia uma crítica contundente à presença do estado na economia enquanto estrategista, criador e promotor do desenvolvimento (MANZETTI, 1999). Neste contexto, a regulação transfiguraria atividade eminentemente técnica, ou melhor, tecnocrática. Assim como em países desenvolvidos, a regulação deveria ser a mais apolítica possível (MAJONE, 1997).

O que transcorreu no Brasil, portanto, resultou de um processo de difusão de reformas e de mimetismo institucional em proporções globais, num efeito "bola-de-neve" (THATCHER, 2002). Ocorre que, como esclarece Fleury (1997), a construção da estrutura de estado no Brasil nunca se deu em saltos, mas em contínuo processo cumulativo de mudança. Existe, na história do estado brasileiro, um nítido padrão de path dependence que constrange reformas e restringe a abrangência de propostas de mudança institucional. Qualquer iniciativa reformista é, em grande medida, influenciada pelos padrões políticos e institucionais pretéritos, resultando, na prática, numa "babel de arranjos institucionais" (GAETANI, 2004, p. 02).

Num sentido mais amplo, importa notar que na literatura dedicada ao tema da regulação em contextos de desenvolvimento retardatário é crescente a preocupação quanto às diferenças intrínsecas da atividade regulatória nessas circunstâncias. Para alguns autores desse campo, haveria que se falar em diferentes tipos e escopo para a regulação, derivados do ambiente próprio em que funcionam governos, mercados e sociedades em desenvolvimento. Prado (2012), Minogue (2002, 2006), Dubash e Morgan (2013), entre outros, ressaltam as características próprias da regulação em contextos de países em desenvolvimento. Esse grupo de autores compreende que questões de natureza não somente econômica, mas também de ordem político-institucional, social e cultural influem decisivamente na prática regulatória, o que justifica um olhar específico para a regulação em vigor no chamado "sul do mundo".

Como relação aos objetivos diferenciados da regulação, Chang (1997) chama a atenção para itens que são de particular importância para países em processos de catching-up, ou seja, que buscam encurtar a distância para o estágio de desenvolvimento em que estão as nações já avançadas. $\mathrm{O}$ autor destaca, primeiro, que impactos distributivos raramente são levados em conta pela regulação tradicional. Chang afirma que, em termos de renda e bem-estar, impactos distributivos não podem ser secundarizados em prol de argumentos de eficiência econômica estática. Chang (1997) também acentua que questões relativas à eficiência dinâmica, ou seja, a processos de inovação e ganhos de produtividade que colaborem para a sofisticação industrial e o crescimento econômico, igualmente não devem ser negligenciados no emprego da regulação. 


\section{REVISTA ESTUDOS INSTITUCIONAIS}

Baldwin et. al. (2012) lembram que o conceito de enraizamento (embeddedness) é fundamental em processos de desenvolvimento, historicamente. Tanto a literatura tradicionalmente desenvolvimentista, por exemplo, Granovetter (1985) e Evans (1995), quanto os mais recentes estudos ligados a correntes novo-desenvolvimentistas no século XXI, como em Boschi (2011), enfatizam a importância dos programas de desenvolvimento envolverem trocas e mútuo aprendizado - inicialmente entre Estado e empresariado e, mais modernamente, também com ênfase no papel dos atores sociais ${ }^{6}$.

Portanto, vê-se nítida a necessidade de uma cuidadosa reflexão sobre como se devem ajustar as regras e políticas estatais levadas a efeito mediante o exercício da regulação em circunstâncias de desenvolvimento e de processos tardios de industrialização. Isto é tendente a impactar tanto na substância quanto no modus operandi da atividade regulatória estatal. Consequentemente, também influi no efeito da regulação - sua efetividade. Segundo Coutinho (2014, p. 112-113):

[seria possível] sustentar que países em desenvolvimento têm características e problemas únicos que parecem sugerir a importância de estratégias e objetivos regulatorios que podem ser distintos daqueles adotados pela regulação 'convencional' do mundo desenvolvido.

Entendida a regulação como uma forma de intervenção estatal prescritiva ou indutiva, conforme descrito acima, interessa esclarecer como as peculiaridades dos países em desenvolvimento devem ser abordadas; e, igualmente, quais arcabouços teóricos podem ser utilizados para interpretá-las. A seguir, serão analisadas alternativas teóricas para tal finalidade, tendo em vista a interdisciplinaridade da regulação, pela ótica do Direito e da Economia.

\footnotetext{
${ }^{6}$ Evans (2011) afirma que os laços Estado-sociedade, construídos pela recorrência e aprimoramento de processos de enraizamento, constituem o principal desafio de estados desenvolvimentistas do século XXI.
} 


\section{REGULAÇÃO E DESENVOLVIMENTO ECONÔMICO: UMA ANÁLISE CRÍTICA E INTERDISCIPLINAR EM DIREITO E ECONOMIA}

\section{VERTENTES EM DIREITO E ECONOMIA - ANÁLISE COMPARADA}

\section{Law \& Economics}

A vertente da Law \& Economics, ou Análise Econômica do Direito, tem objetivo claro: aplicar o método econômico convencional para analisar normas e instituições jurídicas (COOTER; ULEN, 2011). No estudo da interdisciplinaridade entre Direito e Economia, a principal contribuição dessa vertente diz respeito à preocupação com o efeito (impacto) econômico dos dispositivos normativos no comportamento dos indivíduos. Isto é feito, essencialmente, por intermédio do emprego do raciocínio microeconômico neoclássico.

A Análise Econômica do Direito teve seus pilares erguidos especialmente pela influência da Escola de Chicago. Capitaneada por Richard A. Posner, Gary Becker e outros, essa vertente teórica tem a intenção de gerar um arcabouço jurídico economicamente eficiente, assim entendido pela adequação à eficiência estática de tipo paretiana ${ }^{7}$ (SZTAJN, 2005).

Especialmente importante para a argumentação microeconômica ortodoxa - o principal pilar da Law \& Economics - é a noção de adaptação autônoma. Segundo ela, os indivíduos responderiam ao comportamento dos preços no mercado e ajustariam suas expectativas e alocações de recursos de maneira eficiente, por meio da interação entre compradores e vendedores. O que conduziria esse tipo de processo decisório seria o caráter racional e bem informado dos agentes.

A base epistemológica para esta abordagem convencional prómercado está na Teoria do Equilíbrio Geral, cuja raiz está nos estudos de Walras, no final do século XIX. Esta, por sua vez, tem em si o espírito da obra de Adam Smith e o compromisso normativo com a noção de mão invisível do mercado, segundo a qual os agentes, individualmente e de maneira auto interessada, em suas ações e decisões próprias, acabariam, ao cabo, promovendo o bem comum.

Mais claramente, o comportamento atomista e racional do modelo de equilíbrio geral tem relação com as seguintes hipóteses:

I. Perfeita informação - agentes detêm todas as informações relevantes;

\footnotetext{
7 A teoria econômica aponta que, na ausência de interferência externa no sistema econômico, as trocas entre os agentes prosseguiriam enquanto a eles for vantajoso, até o momento em que se atinja o equilíbrio competitivo. Isso prossegue enquanto houver possibilidade de melhorias no sentido de Pareto. Na situação Pareto-eficiente, não é possível melhorar a situação de algum agente sem que se prejudique a de outro, determinando, assim, uma condição de equilíbrio.
} 


\section{REVISTA ESTUDOS INSTITUCIONAIS}

II. Número suficientemente grande de compradores e vendedores, de maneira que nenhum deles pode, individualmente, afetar o mercado (isto é, os preços são dados);

III. Os produtos são homogêneos;

IV. Há livre mobilidade de recursos, sem impedimento à alocação de recursos onde for mais vantajoso;

V. Os mercados são completos, pois há mercado para qualquer produto ou serviço que se queira.

Essas hipóteses, uma vez válidas, garantiriam que os mercados estariam aptos a alocar de forma eficiente recursos e produtos, via flutuações no sistema de preços. Essa lógica interpretativa foi reproduzida para o campo da Análise Econômica do Direito. Cooter e Ulen (2011, p. 03) descrevem essa adaptação:

A Economia proveu um teoria científica para prever os efeitos das sanções legais sobre o comportamento. Para os economistas, sançõ̃es se assemelham a preços, e as pessoas, presumidamente, respondem a essas sanções de forma parecida a como respondem a preços. Indivíduos respondem a preços mais altos consumindo menos do produto; presumidamente, indivíduos também responderão a sanções mais severas adotando menos a conduta objeto da sanção. ${ }^{8}$

Para o método da Law \& Economics, qualquer relação que envolva um caráter normativo e interventivo, inclusive o processo decisório estatal e as políticas públicas em geral, são potenciais objetos de exame pelo esquema adotado por essa vertente analítica (ESTEVES, 2010). O método eleito pela Análise Econômica do Direito permite - segundo seus adeptos - a generalização dos padrões de comportamentos dos indivíduos.

Sendo assim, a Análise Econômica do Direito propugna que as hipóteses preditivas da microeconomia tradicional se aplicam de maneira eficiente também a situações de fora do mercado, e não somente àquelas submetidas ao mundo da tomada de decisões puramente econômicas. Sobre isso, Posner (1987, p. 03) afirma:

a abordagem econômica provou-se frutífera para lidar com assuntos não-econômicos tão diversos quanto

8 Em tradução livre. 


\section{REGULAÇÃO E DESENVOLVIMENTO ECONÔMICO: UMA ANÁLISE CRÍTICA E INTERDISCIPLINAR EM DIREITO E ECONOMIA}

educação, história econômica, as causas da regulação normativa, o comportamento de instituições sem fins lucrativos, divórcio...9.

Assim, a Análise Econômica do Direito buscou determinar o que seriam regras eficientes ao longo dos diversos ramos de aplicação do Direito.

A preocupação da Análise Econômica do Direito com os efeitos das normas é mesmo seu aspecto distintivo. A regulação, que, especialmente nos países de tradição jurídica romano-germânica, materializa-se no mundo real por meio de normas escritas e formalizadas, tem na sua efetividade um dos pontos mais críticos. O raciocínio dedutivo defendido pela Law $\mathcal{E}$ Economics, portanto, pode contribuir para as considerações acerca do impacto das normas regulatórias.

Ainda que a relevância da eficiência alocativa não seja algo restrito à regulação desempenhada em países em desenvolvimento, nestes ela também pode ser buscada. Ademais, mesmo que se entenda a eficiência alocativa como um critério parcial para o julgamento da efetividade da regulação, isto não retira sua importância relativa. Portanto, entende-se coerente afirmar que a análise econômica das regras regulatórias, em linha com a Law \& Economics, pode contribuir para o exame da efetividade dessas regras. Isso se dá no nível micro, ou seja, no campo da escolha das ferramentas regulatórias e da arquitetura decisória ${ }^{10}$.

\section{Nova Economia Institucional}

A Nova Economia Institucional (NEI) empresta útil contribuição, justamente em face dos limites da visão econômica convencional e seu reducionismo na interpretação do processo decisório individual elemento que é incorporado pela Law \& Economics. Embora a NEI não demarque uma ruptura com relação à ortodoxia econômica, ela, conforme esclarece um de seus principais expoentes, Oliver Williamson, "teve suas origens na boa crítica à ortodoxia, acreditando que instituições eram tanto importantes quanto suscetíveis de análise"11 (WILLIAMSON, 2000, p. 600). Instituições formais e informais, que dizem respeito às regras legitimamente instituídas e socialmente enraizadas, são internalizadas no roteiro analítico da NEI. Instituições são secundarizadas pela ortodoxia econômica convencional.

\footnotetext{
9 Em tradução livre.

10 A vinculação com a regulação é ainda mais natural no recente ramo da Behavioral Law and Economics, o qual coloca ainda mais ênfase no que se chama de arquitetura de decisão (choice architecture).

11 Em tradução livre.
} 


\section{REVISTA ESTUDOS INSTITUCIONAIS}

JULHO/DEZEMBRO - ISSN 2447-5467

Embora o campo não seja restrito e comporte diversos autores e objetos de estudo, dois autores pioneiros e mais amplamente citados da NEI são Douglass North e Oliver Williamson. Para North e Williamson assim como para os demais neo-institucionalistas - o papel das instituições, formais e informais, é crucial para a compreensão do funcionamento da economia.

Consequentemente, a relevância dessa vertente teórica para o presente estudo é ímpar. Como afirma Esteves, "as regras formais (não apenas leis, mas também todo o conjunto de atos e políticas governamentais que criam regras para os agentes econômicos e regulam seu comportamento de forma mais ou menos interventiva) são a porção mais evidente das instituições, constituindo um dos principais componentes da estrutura institucional das sociedades" (ESTEVES, 2010, p. 98). Embora avançar sobre o extenso debate teórico acerca do conceito de instituições não seja um objetivo deste trabalho, é relevante reter as instituições como expedientes tanto formais quanto informais. Ambos moldam e determinam as relações humanas e os comportamentos dos indivíduos em sociedade.

Neste trabalho, dada a amplitude e pluralidade da produção da NEI, optou-se for priorizar o exame da chamada Economia dos Custos de Transação (ECT) (ZYLBERSZTAJN; SZTAJN, 2005), cuja fonte seminal são as contribuições de Williamson. Dentre os principais autores neoinstitucionalistas, entende-se que a produção teórica de Williamson sobre as estruturas de governança - ou arranjos institucionais - apoia uma interpretação qualificada das formas alternativas de gestão do sistema econômico, e empresta ferramentas relevantes para o objeto maior deste artigo. Williamson contribui para o exame acerca da institucionalização de uma estrutura regulatória estatal.

Primeiramente, importa notar que, segundo Williamson, existem diferentes arranjos ou matrizes institucionais que propiciam resultados de coordenação e organização tão ou mais eficazes que o mercado (WILLIAMSON, 1996). Isso se torna ainda mais claro em contextos de desenvolvimento, dada a realidade de veloz transformação socioeconômica. Williamson assenta sua análise na importância dos custos de transação, que, sinteticamente, são a expressão econômica das fricções do sistema econômico - ou do conflito, conforme Fiani (2011).

Os delimitadores dos custos de transação estão vinculados a elementos que estão de fora da abordagem econômica convencional, e dizem respeito especialmente a (FIANI, 2011):

I. Racionalidade limitada dos agentes 


\section{REGULAÇÃO E DESENVOLVIMENTO ECONÔMICO: UMA ANÁLISE CRÍTICA E INTERDISCIPLINAR EM DIREITO E ECONOMIA}

II. Incerteza e complexidade dos cenários econômicos;

III. Possibilidades de comportamentos oportunísticos individuais;

IV. Especificidade dos ativos, que diz respeito à perda de valor do ativo econômico se realocado para aplicação diversa daquela para a qual foi originalmente desenhado.

A magnitude e o grau de incidência desses elementos determinam o volume dos custos de transação; e, no mesmo sentido, o tipo de estrutura de governança mais adequado para lidar com eles e propiciar a maior coordenação - e o menor conflito - entre os agentes envolvidos. $\mathrm{O}$ mercado, assim, é apenas um desses tipos de estrutura, a menos especializada de todas. Soma-se a ele a estrutura do tipo hierárquica e a híbrida, que implica diferentes instrumentos para a promoção da coordenação e redução dos conflitos. O quadro 1 descreve como os instrumentos das diferentes estruturas de governança incidem.

Quadro 1 - atributos das estruturas de governança

\begin{tabular}{|c|l|l|l|}
\cline { 2 - 4 } \multicolumn{1}{c|}{} & Mercado & Híbrida & Hierarquias \\
\hline $\begin{array}{c}\text { Incentivos } \\
\text { Administrativos }\end{array}$ & Fortes & Moderados & Ausentes \\
\hline Adaptação Autônoma & Fortes & Moderados & Fortes \\
\hline Adaptação Coordenada & Ausente & Moderada & Forte \\
\hline
\end{tabular}

Fonte: Fiani (2011)

Vale notar que as estruturas híbridas são uma combinação das estruturas dos tipos mercado e hierárquica, por isso a potência moderada em todos os elementos do quadro 1. Contudo, não é correto afirmar que exista um padrão evolutivo ou continuum entre os três tipos de estruturas - o que significaria hierarquiza-los. Simplesmente, há uma melhor adequação de uma ou outra estrutura a casos específicos, a depender essencialmente da especificidade dos ativos e dos demais determinantes dos custos de transação acima listados (FIANI, 2011). O gráfico abaixo ilustra esse ponto, sendo ' $\mathrm{M}(\mathrm{k})$ ' a estrutura de mercado, ' $X(\mathrm{k})^{\prime}$ a híbrida e ' $\mathrm{H}(\mathrm{k})^{\prime}$ a hierárquica. 


\section{REVISTA ESTUDOS INSTITUCIONAIS}

\section{Gráfico 1 - Estruturas de Governança}

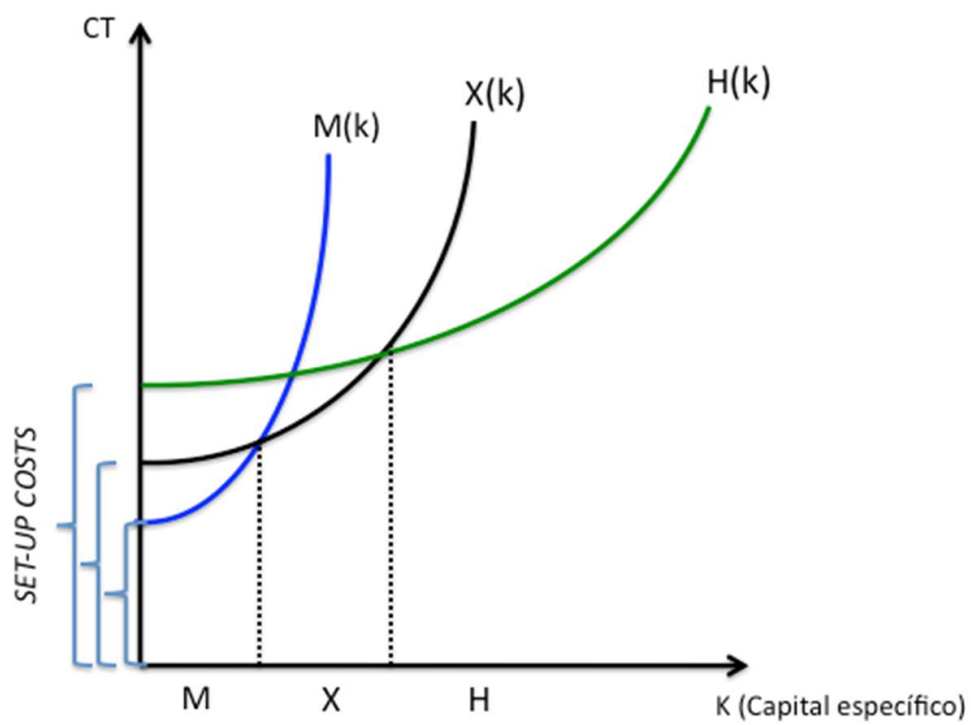

Fonte: adaptado de Williamson (1996)

Ao se analisar o gráfico 1, pode-se notar que qualquer dos tipos de estruturas de governança implica custos de estabelecimento (set-up costs). Cada uma delas se mostrará mais baratas (e, portanto, mais adequadas) de acordo com diferentes magnitudes de ' $K$ '. A depender do nível dos custos de transação e da especificidade do capital investido, haverá estruturas de governança que se ajustam melhor a determinadas situações, dado o objetivo de máxima coordenação econômica e de mínimo conflito. Portanto, o mercado, que tem seu especial valor, somente se apresenta como estrutura preferível, contudo, se perceptíveis os elementos econômico-institucionais que a ele conduzam, notadamente a baixa especificidade de ativos.

Por outro lado, a escolha entre qual das estruturas de governança aplicar não encerra uma decisão racional tal qual a idealizada pela abordagem econômica convencional. Isso porque não se está, na ECT de Williamson, no campo da plena racionalidade, mas sim no da racionalidade limitada.

Nesse sentido, há que se ter em conta a importância do aspecto intertemporal e dinâmico, o que remete às noções de aprendizado, de experimentalismo e de processos evolutivos de contínuos aprimoramentos. Esses aspectos permitem o refinamento das estruturas 


\section{REGULAÇÃO E DESENVOLVIMENTO ECONÔMICO: UMA ANÁLISE CRÍTICA E INTERDISCIPLINAR EM DIREITO E ECONOMIA}

de governança ao longo do tempo (WILLIAMSON, 2000). A racionalidade limitada implica que contratos - notadamente os administrativos - serão sempre incompletos, de modo que lacunas e equívocos são inevitáveis, porém, corrigíveis (CUNHA; GOMIDE; KARAM, 2017). Desse modo, o teste empírico das estruturas de governança respeitará as circunstâncias vigentes, com pouco espaço para o dedutivismo ou prescritivismo lógico da Teoria do Equilíbrio Geral.

Também é relevante destacar que estruturas de regulação compostas por agências reguladoras autônomas e arcabouços legais que prescrevem direitos e responsabilidades a agentes econômicos em setores determinados são claros exemplos de arranjos institucionais híbridos (FIANI, 2011). Como se pode compreender a partir do quadro 1, as estruturas híbridas combinam instâncias de mercado e de hierarquia. Porém, conforme também descrito, estruturas de governança híbridas serão as mais eficazes se e somente se as circunstâncias vigentes conduzirem à sua escolha como arranjo institucional mais adequado, o que propiciará o melhor arranjo para a promoção da cooperação e redução do conflito.

Ou seja, a estrutura de governança que conte com uma agência reguladora responsável pelo monitoramento de um setor econômico específico - modelo utilizado no Brasil para alguns setores cruciais - não se constitui, necessariamente, numa escolha do tipo second-best, ou mesmo num entrave ao mercado e sua eficiência. A realidade fática específica e as preferências sociais em vigor podem assinalar a este tipo híbrido o caráter de melhor opção possível, superior mesmo ao mercado - o qual, portanto, não pode ser sempre assumido como first-best. Vale ressalvar que a NEI, na modalidade desenvolvida por Williamson, é particularmente válida quando se tem em conta que, em contextos de desenvolvimento, conflitos, incertezas, flutuações e perturbações tendem a ser muito mais frequentes do que nas economias avançadas.

Em contextos regulatórios de nações em desenvolvimento, em particular, não será somente a eficiência alocativa estática deve contar como parâmetro para a aferição da performance da regulação. A geração de eficiência dinâmica é condição para avanços produtivos na relação entre Estado e mercado, o que incorpora capacidade de inovação e criação de mercados, ao invés da mera ação correção ou reparatória do Estado (PROSSER, 2006).

Adicionalmente, a estruturação da arquitetura organizacional servente a metas de embeddedness na relação entre Estado, mercado e sociedade podem ser mais bem explicados pela via da economia dos custos de transação. Isto porque, dadas as especificidades de projetos de catching-up, os custos de transação incidentes em cada caso conduzirão a escolhas que podem contribuir para metas de desenvolvimento mais 


\section{REVISTA ESTUDOS INSTITUCIONAIS}

amplas, que não somente as atingíveis via estrutura de governança do tipo mercado.

\section{Direito e Desenvolvimento}

O campo do Direito e Desenvolvimento é tanto mais recente quanto mais fluido do que as duas vertentes anteriores. Isso se deve ao caráter igualmente fluido do conceito de desenvolvimento, que pode ser entendido de uma maneira reducionista ou economicista, priorizando ganhos quantitativos, mas também de um ponto de vista democrático e socialmente dirigido. Neste caso, utilizam-se métricas qualitativas políticas e sociais.

A despeito de sua difícil delimitação, Direito e Desenvolvimento pode ser mais bem compreendido atentando-se à sua finalidade. De acordo com Trubek e Santos (2006, p. 03-04), “a doutrina do Direito e Desenvolvimento orienta e explica as práticas atuais daqueles que procuram modificar sistemas legais em nome do desenvolvimento, seja qual for sua definição"12. Ou seja, os pesquisadores vinculados a esse campo interdisciplinar devem buscar responder à questão: "como pode o Direito resolver ou atenuar o problema do desenvolvimento"13 (PRADO, 2010, p. 14).

Mariana Prado (2010) esclarece que haveria que se falar na existência de dois grandes grupos a compor o campo do Direito e Desenvolvimento. O primeiro deles pode ser conceituado como "Direito no [ou para] o Desenvolvimento". Aqui, o Direito assume feição instrumental para o desenvolvimento. Neste caso, modelos de desenvolvimento diferentes e rivais, como o neoliberal e o desenvolvimentista, disputariam terreno nos campos teórico e prático.

O segundo grupo é aquele a ser definido como o do "Direito como Desenvolvimento". Neste, o desenvolvimento assume caráter próprio, sendo o Direito não somente instrumental. Entendido especialmente por meio da conceituação dada por Amartya Sen (1999), desenvolvimento seria visto como liberdade, isto é, como o processo de empoderamento dos indivíduos para que eles detenham meios suficientes para poderem, livremente, gerenciar suas próprias vidas e escolhas. Neste contexto, os direitos fundamentais e aqueles vinculados às liberdades políticas, sociais, culturais tornam-se peças integrantes do conceito de

\footnotetext{
12 Em tradução livre.

13 Em tradução livre.
} 


\section{REGULAÇÃO E DESENVOLVIMENTO ECONÔMICO: UMA ANÁLISE CRÍTICA E INTERDISCIPLINAR EM DIREITO E ECONOMIA}

desenvolvimento - independentemente dos resultados práticos ou mensuráveis.

O que é particularmente importante na crescente produção acadêmica em Direito e Desenvolvimento é o foco no papel do Direito em processos de desenvolvimento econômico no estágio "pós-neoliberal", entendido como o momento que sucedeu às reformas liberalizantes dos anos $1990 \mathrm{e}$ início dos anos 2000 (TRUBEK et al., 2013). A etapa anterior a esta, de elevada influência do neoliberalismo, coincidiu com um Direito mais formalista, e focado na estabilidade de regras que assegurassem e previsibilidade do ambiente de negócios, além de restringir o papel do Estado na economia (TRUBEK; SANTOS, 2006).

$\mathrm{Na}$ fase pós-neoliberal, inaugurou-se em alguns países ideias de cunho neo-desenvolvimentista (ou novo desenvolvimentista), que representam um misto - ou síntese - entre modelos de desenvolvimento. No que importa ao Brasil, Ban (2013) posiciona-se acerca da existência de um estado "liberal neo-desenvolvimentista". O autor descreve que, ao longo da última década, o Brasil, ao mesmo tempo em que avançou na função de regulador - em linha com uma versão liberalizante do Estado -, não retraiu o caráter intervencionista em setores chaves da economia (BAN, 2013). Musacchio e Lazzarini (2014) posicionam-se de maneira similar.

No estágio pós-neoliberal, o Direito, ao contrário do perfil assumido no estágio antecedente, assume funções consequencialistas. Ou seja, passa a ser visto de uma maneira funcional, no que tange a seus efeitos sobre o desenvolvimento (TRUBEK; SANTOS, 2006). Há que se destacar a diferença com respeito à preocupação quanto aos efeitos presente também na vertente do Law $\mathcal{E}$ Economics. Neste caso, o foco está na eficiência econômica alocativa. $\mathrm{O}$ emprego do consequencialismo pelo Direito e Desenvolvimento presta-se, por outro lado, à busca da interpretação da estrutura jurídica e das normas quanto ao alinhamento a propósitos de desenvolvimento. É, portanto, um processo de engenharia reversa, segundo o qual "se deve começar das políticas e programas, descrevendo as funções associadas a elas e, daí, analisando se o Direito contribuiu ou poderia vir a contribuir para essas funções" (TRUBEK et al., 2013, p. 55).

Nesse novo papel ativo, proporcional ao ativismo estatal no pósneoliberalismo, Trubek et al. (2013) entendem que o Direito deve passar a assumir quatro novos papéis:

I. Assegurar flexibilidade - facilitar experimentação, feedback, inovação e novas formas de governança;

II. Estimular atuação orquestrada entre Estado e sociedade - facilitar articulação horizontal e vertical e a compreensão mútua;

III. Estruturar sinergias - impulsionar associações público-privadas; 


\section{REVISTA ESTUDOS INSTITUCIONAIS}

IV. Garantir legitimidade e menos autoritarismo- assegurar transparência e participação.

Dessa maneira, pode-se coerentemente relacionar o ramo do Direito e Desenvolvimento à regulação nos países emergentes, tanto de forma ampla quanto restrita. No último caso, a associação seria via consequencialismo e o emprego de ferramentas de policy analysis ao Direito. À semelhança da Análise Econômica do Direito, a interpretação quanto aos efeitos das normas toma papel de destaque. O que distingue radicalmente estas duas vertentes, na esfera da efetividade das normas, é o fato de que, em Direito e Desenvolvimento, o que importa é a contribuição do Direito para o alcance de metas de desenvolvimento, e não a busca específica de eficiência econômica stricto sensu.

Em segundo lugar, de um ponto de vista macro-institucional, a vertente do Direito e Desenvolvimento pode auxiliar a que normas regulatórias se coadunem melhor com a agenda de desenvolvimento, desde que se leve em conta, na confecção da regulação, os quatro papéis que o Direito deve assumir, listados acima. Como já tratado neste trabalho, o conceito de embeddedness é relevante em processos e políticas de desenvolvimento. No campo da regulação aplicada a países em desenvolvimento, Baldwin et al. (2012) advertem que o regime regulatório deve envolver a construção de legitimidade na interação constante entre os agentes econômicos e atores sociais, no processo de embedding. Portanto, neste ponto, os autores convergem com a vertente do Direito e Desenvolvimento.

\section{CONCLUSÂO}

O que se pode notar é que uma agenda de pesquisa que se proponha a conciliar a moderna atuação do Estado vinculada ao desempenho de suas atividades regulatórias e o avanço de processos de desenvolvimento econômico democráticos embute a investigação sobre fatores tanto peculiares às nações periféricas quanto transversais à prática regulatória, indistintamente. Apesar do modus operandi da regulação ensejar questões comuns entre os países desenvolvidos e nações emergentes, este artigo argumentou que existem elementos para os quais se deve atentar mais detidamente - senão exclusivamente - quando se reflete acerca da regulação em economias em transição.

Neste artigo, também foi possível identificar a aplicabilidade das três vertentes de Direito e Economia apresentadas, no que tange à estruturação e ao emprego da regulação em contextos de 


\section{REGULAÇÃO E DESENVOLVIMENTO ECONÔMICO: UMA ANÁLISE CRÍTICA E INTERDISCIPLINAR EM DIREITO E ECONOMIA}

desenvolvimento. A interdisciplinaridade levada a efeito seja pelo método da Análise Econômica do Direito, seja pela Nova Economia Institucional ou pela lente do Direito e Desenvolvimento indicam que contextos de desenvolvimento são complexos e merecem, para serem enfrentados, múltiplas e complementares abordagens.

$\mathrm{O}$ quadro 2 indica os pontos fortes, moderados e fracos das três vertentes em Direito e Economia, no tocante à regulação. Com ele, podese notar a pertinência do emprego associado das três.

Quadro 2 - síntese das três vertentes em direito e economia

\begin{tabular}{|l|c|c|c|}
\cline { 2 - 4 } \multicolumn{1}{c|}{} & $\begin{array}{c}\text { Law E } \\
\text { Economics }\end{array}$ & $\begin{array}{c}\text { Economia dos } \\
\text { Custos de } \\
\text { Transação }\end{array}$ & $\begin{array}{c}\text { Direito e } \\
\text { Desenvolvimento }\end{array}$ \\
\hline $\begin{array}{l}\text { Aspectos Macro- } \\
\text { institucionais da regulação }\end{array}$ & Fraco & Moderado & Forte \\
\hline $\begin{array}{l}\text { Estrutura de governança } \\
\text { da regulação }\end{array}$ & Fraco & Forte & Moderado \\
\hline $\begin{array}{l}\text { Arquitetura organizacional } \\
\text { do órgão regulador }\end{array}$ & Moderado & Forte & Fraco \\
\hline Efetividade da regulação & Forte & Moderado & Forte \\
\hline
\end{tabular}

Fonte: elaboração própria

Como se nota no quadro 2, pode haver complementariedade entre as três vertentes teóricas apresentadas. A Law $\mathcal{E}$ Economics tem seu ponto forte em níveis micro, o que a difere, em grande medida, da vertente do Direito e Desenvolvimento. Contudo, a última também se prova eficaz na reflexão sobre elementos intra-agências reguladoras, os quais atenderiam à efetividade da regulação. A NEI, por seu turno, tem nas camadas meso, isto é, de governança, sua maior eficácia. Assim, a estruturação de regimes e agências reguladoras sob o amparo da NEI e de interpretações que ponderem custos de transação pode se mostrar vantajosa.

A respeito da necessária interdisciplinaridade tratada neste artigo, vale fazer referência à síntese oferecida por Mariana Prado (2010, p. 23):

... os acadêmicos que adotam hipóteses econômicas fortes (os indivíduos são atores racionais auto-interessados que respondem a incentivos) tendem a crer que o Direito é uma ferramenta muito efetiva para modificar o comportamento humano. Por outro lado, os acadêmicos que são mais abertos às ciência sociais $\mathrm{e}$ consequentemente crêem que a dinâmica social e o comportamento individual não estão unicamente guiados pela racionalidade econômica se perguntam 


\section{REVISTA ESTUDOS INSTITUCIONAIS}

JULHO/DEZEMBRO - ISSN 2447-5467

acerca do potencial do Direito para promover efetivamente mudanças sociais. ${ }^{14}$

Portanto, argumenta-se que está em plena construção uma veia interpretativa que ofereça uma moldura analítica que aporte à regulação tanto objetivos inescapáveis de eficiência econômica e estabilidade institucional quanto a necessária flexibilidade que processos de desenvolvimento requerem. Entende-se que, para isso, é produtivo o estudo comparativo e o emprego conjugado de teorias em áreas tangenciadas pelo Direito e a Economia.

\section{REFERÊNCIAS}

BALDWIN, Robert; CAVE, Martin; LODGE, Martin. Understanding regulation: theory, strategy, and practice. Oxford University Press on Demand, 2012.

BOSCHI, Renato Raul (Ed.). Variedades de capitalismo, política e desenvolvimento na América Latina. Editora UFMG, 2011.

CHANG, Ha-Joon. The economics and politics of regulation. Cambridge Journal of Economics, v. 21, n. 6, p. 703-728, 1997.

COOTER, Robert; ULEN, Thomas. Law and Economics. Glenview. IL: Scott Fores-man, 1988.

BAN, Cornel. Brazil's liberal neo-developmentalism: New paradigm or edited orthodoxy?. Review of International Political Economy, v. 20, n. 2, p. 298-331, 2013.

COUTINHO, Diogo Rosenthal. Direito e economia política na regulação de serviços públicos. Editora Saraiva, 2017.

\footnotetext{
${ }^{14}$ Em tradução livre.
} 


\section{REGULAÇÃO E DESENVOLVIMENTO ECONÔMICO: UMA ANÁLISE CRÍTICA E INTERDISCIPLINAR EM DIREITO E ECONOMIA}

CUNHA, Bruno Q.; RODRIGO, Delia. Regulatory governance in Brazil: inconsistent coordination, institutional fragmentation and halfway reforms. In: 4th biennial ECPR Standing Group for Regulatory Governance Conference, University of Exeter, UK. 2012. p. 27-29.

CUNHA, Bruno Queiroz; GOMIDE, Alexandre de Ávila; KARAM, Ricardo Antônio de Souza. Governança e Capacidade Regulatória: notas de pesquisa. Governança e Capacidade Regulatória: notas de pesquisa.

Boletim de Análise Política-Institucional (BAPI). Instituto de Pesquisa Econômica Aplicada (IPEA), v. 10, n. jul-dez, p. 47-53.

DUBASH, Navroz K.; MORGAN, Bronwen (Ed.). The rise of the regulatory state of the south: Infrastructure and development in emerging economies. Oxford: Oxford University Press, 2013.

ESTACHE, Antonio; WREN-LEWIS, Liam. Toward a theory of regulation for developing countries: Following jean-jacques laffont's lead. Journal of Economic Literature, v. 47, n. 3, p. 729-70, 2009.

ESTEVES, Heloisa B. B. Economia e Direito: um diálogo possível. 2010. Tese de Doutorado. Programa de Pós-Graduação em Economia/IE/UFRJ, 2010.

EVANS, Peter B. Embedded autonomy: States and industrial transformation. Princeton University Press, 2012.

EVANS, Peter B. The capability enhancing developmental state: concepts and national trajectories. Texto para Discussão, no . 63. Niterói: Cede.

FARIAS, Pedro César Lima de; RIBEIRO, Sheila Maria Reis. Regulação e os novos modelos de gestão no Brasil. Revista do Serviço Público, v. 53, n. 3, p. 79-94, 2014.

FEINTUCK, Mike. Regulatory rationales beyond the economic: In search of the public interest. In: The Oxford handbook of regulation. 2010. 


\section{REVISTA ESTUDOS INSTITUCIONAIS}

FIANI, Ronaldo. Cooperação e conflito: instituições e desenvolvimento econômico. Elsevier Brasil, 2011.

FLEURY, Sonia. Programa de Estudos e Pesquisa em Reforma do Estado e Governança. Revista de Administração Pública (RAP), v. 31, n. 4, p. 299-309.

GAETANI, Francisco. Políticas de Gestão Pública e Políticas Regulatórias: contrastes e interfaces. 2004. IX Congreso Internacional del CLAD sobre la Reforma del Estado y de la Administración Pública. Madri, Espanha. Disponível em:

$<$ http://www.bresserpereira.org.br/Documents/MARE/TerceirosPapers/05Gaetani_dic.pdf $>$. Acesso em: 26/11/2018.

GRANOVETTER, Mark. Economic action and social structure: The problem of embeddedness. American journal of sociology, v. 91, n. 3, p. 481-510, 1985.

JORDANA, Jacint; LEVI-FAUR, David (Ed.). The politics of regulation: Institutions and regulatory reforms for the age of governance. Edward Elgar Publishing, 2004. Lodge, M. e Wegric, K. (2012). “Managing Regulation - Regulatory Analysis, Politics and Policy". Palgrave Macmillan.

LODGE, Martin; WEGRICH, Kai. Managing Regulation: Regulatory Analysis, Politics and Policy. Nova Iorque: Palgrave Macmillan, 2012.

MAJONE, Giandomenico. From the positive to the regulatory state: causes and consequences of changes in the mode of governance. Journal of public policy, v. 17, n. 2, p. 139-167, 1997.

MANZETTI, Luigi. Privatization South American Style. Oxford University Press on Demand, 1999. 


\section{REGULAÇÃO E DESENVOLVIMENTO ECONÔMICO: UMA ANÁLISE CRÍTICA E INTERDISCIPLINAR EM DIREITO E ECONOMIA}

MARTINEZ-GALLARDO, Cecilia; MURILLO, Maria Victoria. Agency under constraint: Ideological preferences and the politics of electricity regulation in Latin America. Regulation \& Governance, v. 5, n. 3, p. 350-367, 2011.

MARTINS, Ricardo Marcondes. Regulação Administrativa à Luz da Constituição Federal. São Paulo: ed. Malheiros, 2011.

MATTOS, Paulo Todescan Lessa. O Novo Estado Regulador Brasileiro: eficiência e legitimidade. São Paulo: Ed. Singular, 2006.

MINOGUE, Martin. Governance-Based Analysis of Regulation. Annals of Public and Cooperative Economics, v. 73, n. 4, p. 649-666, 2002.

MINOGUE, Martin. Apples and oranges: comparing international experiences in regulatory reform. In: CARIÑO, Levidina e MINOGUE, Martin (eds). Regulatory Governance in Developing Countries.

Edward Elgar, 2006.

MORAN, Michael. The British regulatory state: high modernism and hyperinnovation. Oxford University Press on Demand, 2003.

MUSACCHIO, A; LAZZARINI, S. G. Reinventing state capitalism: Leviathan in business, Brazil and beyond. Cambridge: Harvard University Press, 2014.

OGUS, Anthony. Regulation: the public interest and the private interest. In: DEFFAINS, Bruno; KIRAT, Thierry (eds). Law and Economics in Civil Law Countries. Elsevier Science, 2001.

OGUS, Anthony. Regulation - Legal Form and Economic Theory. Hart Publishing, 2004.

PELTZMAN, Sam. Toward a more general theory of regulation. The Journal of Law and Economics, v. 19, n. 2, p. 211-240, 1976.

POSNER, Richard A. The law and economics movement. The American Economic Review, v. 77, n. 2, p. 1-13, 1987. 


\section{REVISTA ESTUDOS INSTITUCIONAIS}

PRADO, Luiz Carlos Delorme. Defesa da Concorrência e Desenvolvimento: Notas sobre o Debate e sua aplicação no caso brasileiro. Texto para Discussão 011-2013. Instituto de Econômica da UFRJ, 2013.

PRADO, Luiz Carlos Delorme. Relações entre Estado e Mercado: Reformas e Agências Reguladoras no Brasil, 1991-2013. In: EARP, F. S.; BARSTIAN, E. F.; MODENESI, A. de M. (Eds.). Como Vai o Brasil? A Economia Brasileira no Terceiro Milênio. Rio de Janeiro, Brasil: Imã Editora, 2014.

PRADO, Mariana Mota. Qué es ‘Derecho y Desarrollo'? Revista Argentina de Teoria Jurídica, v. 11, n. 1, 2010.

PRADO, Mariana Mota. Implementing independent regulatory agencies in Brazil: The contrasting experiences in the electricity and telecommunications sectors. Regulation \& Governance, v. 6, n. 3, p. 300-326, 2012.

PROSSER, Tony. Law and the Regulators. Oxford University Press, 1997.

PROSSER, Tony. Regulation and social solidarity. Journal of Law and Society, v. 33, n. 3, p. 364-387, 2006.

SARAVIA, Enrique. Introdução à Teoria da Política Pública. In: SARAVIA, Enrique; FERRAREZI, Elisabete. Políticas Públicas Coletânea, v. I, ENAP, 2006.

SEN, Amartya. Development as Freedom. Oxford University Press, 1999.

STIGLER, George J. The theory of economic regulation. The Bell journal of economics and management science, p. 3-21, 1971. 


\section{REGULAÇÃO E DESENVOLVIMENTO ECONÔMICO: UMA ANÁLISE CRÍTICA E INTERDISCIPLINAR EM DIREITO E ECONOMIA}

SUNSTEIN, Cass R. After the rights revolution: reconceiving the regulatory state. Harvard University Press, 1993.

SZTAJN, Rachel. Law and economics. Direito \& economia: análise econômica do Direito e das organizações. Rio de Janeiro: Elsevier, 2005.

THATCHER, Mark. Delegation to Independent Regulatory Agencies: Pressures, Functions and Contextual Mediation. West European Politics, v. 25, n. 1, p. 125-147, 2002.

TRUBEK, David M.; SANTOS, Alvaro (Ed.). The new law and economic development: a critical appraisal. Cambridge University Press, 2006.

TRUBEK, David M. et al. (Ed.). Law and the new developmental state: the Brazilian experience in Latin American context. Cambridge University Press, 2013.

VELJANOVSKI, Cento. Economic approaches to regulation. In: The 641 Oxford Handbook of Regulation. 2010.

WILLIAMSON, Oliver E. The mechanisms of governance. Oxford University Press, 1996.

WILLIAMSON, Oliver E. The new institutional economics: taking stock, looking ahead. Journal of economic literature, v. 38, n. 3, p. 595-613, 2000.

YEUNG, Karen. The Regulatory State. In: The Oxford Handbook of Regulation. 2010.

ZYLBERSZTAJN, Decio; SZTAJN, Rachel. Direito e economia: análise econômica do direito e das organizações. Rio de Janeiro: Campus, 2005. 